Annals of International Medical and Dental Research

E-ISSN: 2395-2822 | P-ISSN: 2395-2814

Vol-8, Issue-1 | January-February 2022

DOI: 10.53339/aimdr.2022.8.1.25

Page no- 185-191 Section- Research Article (Pharmacology)

\title{
Evaluation of the In Vitro Cytotoxicity of Silver Nanoparticles on PBMC Cells Using MTT Assay
}

\author{
Anish Stephen1, Mahesh Kumar D ${ }^{2 *}$
}

1Assistant Professor, Department of Pharmacology, PK Das Institute of Medical sciences, Vaniamkulam, Ottapalam, Kerala, India. Email: anishstephen@gmail.com Orcid ID: 0000-0002-7941-8754

2Associate Professor, Department of Pharmacology, PK Das Institute of Medical sciences, Vaniamkulam, Ottapalam, Kerala, India. Email: saakethbhagat@gmail.com, Orcid ID: 0000-0002-0535-601X

${ }^{*}$ Corresponding author

Received: 15 September 2021

Revised: 16 November 2021

Accepted: 24 November 2021

Published: 22 December 2021

\begin{abstract}
Background: Silver Nanoparticles are extensively studied by the scientific community for therapeutic applications. With respect to the fundamental pillars of bioethics "Primum non nocere" equal emphasis should be given to evaluate the toxicological perspectives of Silver nanoparticles. This study aims at evaluating the InVitro cytotoxic effects of Silver nanoparticles synthesized using hesperidin. Aim: To study the In Vitro cytotoxicity of silver nanoparticles on PBMC cells using (3-(4,5-Dimethylthiazol-2-yl)-2, 5diphenyltetrazolium bromide (MTT) assay. Methods: Synthesized silver nanoparticles at various concentrations are incubated with peripheral blood mononuclear cells (PBMC). After 24 hours MTT is added to the mixture to evaluate the cell viability post incubation. Yellow MTT (a tetrazole) which is reduced to purple formazan in the mitochondria of living cells. The absorbance of this colored solution can be quantified by measuring at $570 \mathrm{~nm}$ by a spectrophotometer. This reduction takes place only when mitochondrial reductase enzymes are active, and therefore conversion can be directly related to the number of viable (living) cells. Results: ?. Conclusion: Silver Nanoparticles do not exhibit any significant cytotoxicity on PBMCs and also there were no dose dependent trends in the results.
\end{abstract}

Keywords:- Silver Nanoparticles, Hesperidin, Cytotoxicity.

\section{INTRODUCTION}

Exploring the pharmacological profile of silver nanoparticles synthesized using various plant extracts is the dawn of a new era in the utility perspective of silver nanoparticles. Exploring silver nanoparticles from the pharmacological perspective has gained momentum over the last several years. Many research studies have uncovered various obscurities in the link between silver nanoparticles and their claimed health benefits. The use of nanoparticles in medicine, particularly silver nanoparticles, dates back to $1500 \mathrm{BC}$ and has reference in Charaka Samhita.

Silver nanoparticles preparations are referred to as Bhasmas which are well known since the $7^{\text {th }}$ century AD and are unique Ayurvedic metallomineral preparations treated with herbal extracts and heated to a required level as mentioned by the Puta system of Ayurveda. Studies have found out that Bhasmas are biologically produced nanoparticles, which have therapeutic potential in various chronic disorders and are given along with other 
Annals of International Medical and Dental Research E-ISSN: 2395-2822 | P-ISSN: 2395-2814 Vol-8, Issue-1 | January-February 2022 DOI: 10.53339/aimdr.2022.8.1.25

Page no- 00-00 | Section- Research Article (Pharmacology)

medications in the branch of Ayurveda and Siddha medicine respectively.[1]

Modern-day research has scientifically documented various properties of silver nanoparticles which can form a basis for further trials and product development. One of the most commonly studied utilities of silver nanoparticles in medicine is its antimicrobial property, which has helped silver nanoparticles pave its their way into many consumer products like clothing and children's toys, dietary supplements, detergents, body soap, toothbrushes, toothpaste, disinfectants sprays, kitchen utensils. [2] Several studies have shown that silver nanoparticles act against a wide range of bacteria and that antimicrobial properties of silver nanoparticles are strainspecific, [3] and even extends to antibioticresistant bacteria. [4] The therapeutic properties of silver nanoparticles can add value to the utility of a particular product. One such study explored the impregnation of silver nanoparticles into the novel wound dressing material bacterial cellulose. Bacterial cellulose is used in wound dressing since it provides a moist environment to a wound which helps in better wound healing. On the contrary, bacterial cellulose lacks an effective antimicrobial activity because of which there can be detrimental effects on the wound healing process due to wound infection. In order to bestow an antimicrobial activity on the bacterial cellulose-based dressing material, silver nanoparticles were impregnated onto it. The result was that the silver nanoparticles enhanced bacterial cellulose, exhibited strong antimicrobial activity against the gram-positive Staphylococcus aureus and gram-negative Escherichia coli.[5] The effectiveness of silver nanoparticles as antibacterial agents against both aerobic and anaerobic bacteria is supported by a huge number of research studies. The central idea derived from these studies is that silver in nanoparticle form when compared with its ionic form seems to have reduced cellular toxicity without compromising on its antibacterial efficacy.[6] Literature search reveals that silver nanoparticles are also efficacious antiviral agents. In one of the studies, it was found that silver nanoparticles undergo a size-dependent and specific interaction with HIV-1.[7] Similarly, antiviral activities are observed against Respiratory syncytial virus, []] Monkeypox virus, []] Influenza virus,[10] and Hepatitis B Virus.[11] Silver nanoparticles have also proven antifungal activity against a wide range of pathological fungi affecting humans, animals and also plants. Some of the observed antifungal activities were against Candida spp.[12] against Saccharomyces cerevisiae probably through destruction of membrane integrity.[13] Silver Nanoparticles are also effective against plasmodium. [14] Silver nanoparticles are extensively researched with special emphasis on their synthesis using various environmentally benign methodologies. Research has elevated the utility perspective of synthesized silver nanoparticles to higher levels and set a platform to conduct further research with an intention to benefit mankind in the form of Novel therapeutics and drug delivery systems. On a comparative note, the magnitude of work done on the toxicological aspects of silver nanoparticles are very less when compared to its synthesis and its pharmacological evaluation. The significance of the toxicological profile is at par with its therapeutic profile. Irrespective of the level of 
Annals of International Medical and Dental Research

E-ISSN: 2395-2822 | P-ISSN: 2395-2814

Vol-8, Issue-1 | January-February 2022

DOI: $10.53339 /$ aimdr.2022.8.1.25

Page no- 00-00 | Section- Research Article (Pharmacology)

therapeutic efficacy, only particles which are deemed free of toxicological properties will find a place in future research and subsequent applications in humans. The Literature study reveals very few toxicological evaluations done on silver nanoparticles using OECD guidelines. Toxicological profiles of silver nanoparticles have multiple determinants, one of them being the size. One such study has compared the effects of silver nanoparticles with multiple sizes (20,80 and $113 \mathrm{~nm})$ using in vitro assays for inflammation, cytotoxicity, genotoxicity and developmental toxicity. Silver nanoparticles exerted their effect on all the toxicological parameters with maximal effect on membrane damage and cellular metabolic activity at the small size of $20 \mathrm{~nm}$. [15] In a similar study, acute oral toxicity, corrosion and dermal toxicity effects on the eye by colloidal silver nanoparticles (AgNPs) were evaluated in mice and guinea pigs which indicated anLD50 of colloidal AgNPs to more than 5,000 mg/ kg body weight with no significant abnormality on the skin and eye exposure.[16] Among the sparsely available literature, a wide range of outcomes in toxicity have been documented which highlights a significant versatility that which can be attributed to various known and unknown factors and this warrants a need for evaluating the toxicity profile of silver nanoparticles synthesized using different methodologies on study-to-study basis.

In this study, Silver nanoparticles are synthesized using Hesperidin as a capping agent and hence the toxicological perspectives of this product needs to be determined as there is a huge variation in the results exhibited by silver nanoparticles which are evidenced by the literature review.

\section{MATERIAL AND METHODS}

\section{Synthesis of Silver Nanoparticles using phytochemical Hesperidin and its characterization}

Silver Nanoparticles were synthesized using "1 mm silver nitrate $-300 \mu \mathrm{gm} / \mathrm{mL}$ hesperidin" by eco-friendly reduction method.[17]

Spectrophotometric studies on synthesized silver nanoparticles confirmed the synthesis of silver nanoparticles in colloid solution with acceptable qualitative properties

\section{In Vitro Evaluation of cytotoxicity of silver} nanoparticles synthesized using hesperidin

a) Isolation of Red Blood cells and Peripheral blood mononuclear cells.

Informed consent of the volunteer was taken. The volunteer was healthy and had not taken any anti-inflammatory intervention in the last two weeks. No history of inflammatory / allergic diseases in the volunteer.

Fresh whole human blood $(5 \mathrm{ml})$ was collected in EDTA tubes and centrifuged. The tubes were centrifuged at $3000 \mathrm{rpm}$ for $10 \mathrm{~min}$ and were washed three times with an equal volume of normal saline. The volume of blood was measured and reconstituted as $10 \% \mathrm{v} / \mathrm{v}$ suspension with normal saline. Peripheral blood mononuclear cells (PBMCs) were isolated by density gradient centrifugation. $5 \mathrm{ml}$ of whole anti-coagulated blood was added to sterile phosphate buffer saline (PBS) for a total volume of $10 \mathrm{ml}$ in a $50 \mathrm{ml}$ conical flask. The diluted blood samples were carefully layered on $7.5 \mathrm{ml}$ of Ficoll-Paque PLUS (GE Healthcare). The mixture was centrifuged at $400 \mathrm{Xg}$ for 20 min at room temperature and PBMCs layer 
Annals of International Medical and Dental Research

E-ISSN: 2395-2822 | P-ISSN: 2395-2814

Vol-8, Issue-1 | January-February 2022

DOI: $10.53339 /$ aimdr.2022.8.1.25

Page no- 00-00 | Section- Research Article (Pharmacology)

collected at diluted plasma/Ficoll interface. Cells were maintained in RPMI-1640 (Hi-media, India) containing $2 \mathrm{mM}$ glutamine, 10\% heatinactivated fetal bovine serum (HyClone Laboratories, Inc., Logan, UT, USA), 50 U/mL penicillin, $50 \mu \mathrm{g} / \mathrm{mL}$ streptomycin, and antimycotic agents (GIBCO-Invitrogen) in a humidified atmosphere at $37^{\circ} \mathrm{C}$ and $5 \% \mathrm{CO} 2$. Cell numbers were determined using a hemocytometer.

b) In Vitro cytotoxicity of silver nanoparticles on PBMC cells using (3-(4, 5-Dimethylthiazol-2-yl)-2, 5 diphenyltetrazolium bromide (MTT) assay.

\section{Materials:}

MTT was sourced from Sigma Aldrich. Separated PBMCs resuspended in RPMI 1640 (Hi Media, India) supplemented with 10\% FBS were used.

\section{Principle:}

Yellow MTT (a tetrazole) is reduced to purple formazan in the mitochondria of living cells. The absorbance of this coloured solution can be quantified by measuring at $570 \mathrm{~nm}$ by a spectrophotometer. The absorption max is dependent on the solvent employed. This reduction takes place only when mitochondrial reductase enzymes are active, and therefore conversion can be directly related to the number of viable (living) cells. When the amount of purple formazan produced by cells treated with an agent is compared with the amount of formazan produced by untreated control cells, the effectiveness of the agent in causing the death of cells can be deduced, through the production of a dose-response curve. Solutions of MTT solubilized in tissue culture media or balanced salt solutions, without phenol red, are yellowish in colour. Mitochondrial dehydrogenases of viable cells cleave the tetrazolium ring, yielding purple MTT formazan crystals which are insoluble in aqueous solutions. The crystals are dissolved in dimethyl sulfoxide (DMSO). The resulting purple solution is measured using a spectrophotometer. An increase in cell number results in an increase in the amount of MTT formazan formed and an increase in absorbance. The use of the MTT method does have limitations influenced by: (1) the physiological state of cells and (2) variance in mitochondrial dehydrogenase activity in different cell types. Nevertheless, the MTT method of cell determination is useful in the measurement of cell growth in response to mitogens, antigenic stimuli, growth factors and other cell growth-promoting reagents, cytotoxicity studies, and in the derivation of cell growth curves.

\section{Procedure:}

Silver Nanoparticles synthesized using Hesperidin were subjected to a 5-point titration of two-fold dilutions with a high standard of $200 \mu \mathrm{gm} / \mathrm{mL}$ of double distilled water and the following conc. were prepared $100 \mu \mathrm{gm} / \mathrm{mL}$, $50 \mu \mathrm{gm} / \mathrm{mL}, 25 \mu \mathrm{gm} / \mathrm{mL}$ and $12.5 \mu \mathrm{gm} / \mathrm{mL}$. Ninety $\mu$ containing $1 \times 105$ PBMC cells/well were seeded in a 96- well plate. After 6 hours of incubation time, $10 \mu l$ containing silver nanoparticles synthesized using Hesperidin in the following concentrations $200 \mathrm{mg} / \mathrm{mL}$, $100 \mathrm{mg} / \mathrm{mL}, 50 \mathrm{mg} / \mathrm{mL}, 25 \mathrm{mg} / \mathrm{mL}$ and $12.5 \mathrm{mg}$ $/ \mathrm{mL}$ were added. They were allowed to incubate for 24 hours at $37^{\circ} \mathrm{C}$ in a humidified condition containing 5\% CO2. After 24 hours, 20 
Annals of International Medical and Dental Research

E-ISSN: 2395-2822 | P-ISSN: 2395-2814

Vol-8, Issue-1 | January-February 2022

DOI: 10.53339/aimdr.2022.8.1.25

Page no- 00-00 | Section- Research Article (Pharmacology)

$\mu \mathrm{l}$ of $5 \mathrm{mg} / \mathrm{mL}$ MTT was added into each well in the 96-well plate and incubated for 4 hours at $37^{\circ} \mathrm{C}$ in a humidified environment containing $5 \%$ CO2 .Subsequently, the medium was removed from every well, and $200 \mu$ of DMSO was added to dissolve the formazan crystal. In the control, distilled water not containing the silver nanoparticles was used. The absorbance was measured at $595 \mathrm{~nm}$.

The percentage of cell viability was calculated using the following formula:

$\%$ cell viability $=$

Absorbance (control) -Absorbance (Test) $\times 100$

Absorbance (control)

Test Compound: Silver nanoparticles synthesized using Hesperidin
All the readings were taken in triplicate and their mean value was taken in consideration. Results were expressed as Mean \pm Standard Error of mean (SEM).

\section{Statistical analysis}

Wilcoxon signed-rank test to check the difference in values of each concentration with that of the control.

\section{RESULTS}

a. In vitro evaluation of cytotoxicity of silver nanoparticles on peripheral blood mononuclear cells using MTT Assay

Results are expressed as Mean \pm Standard Error of mean (SEM).

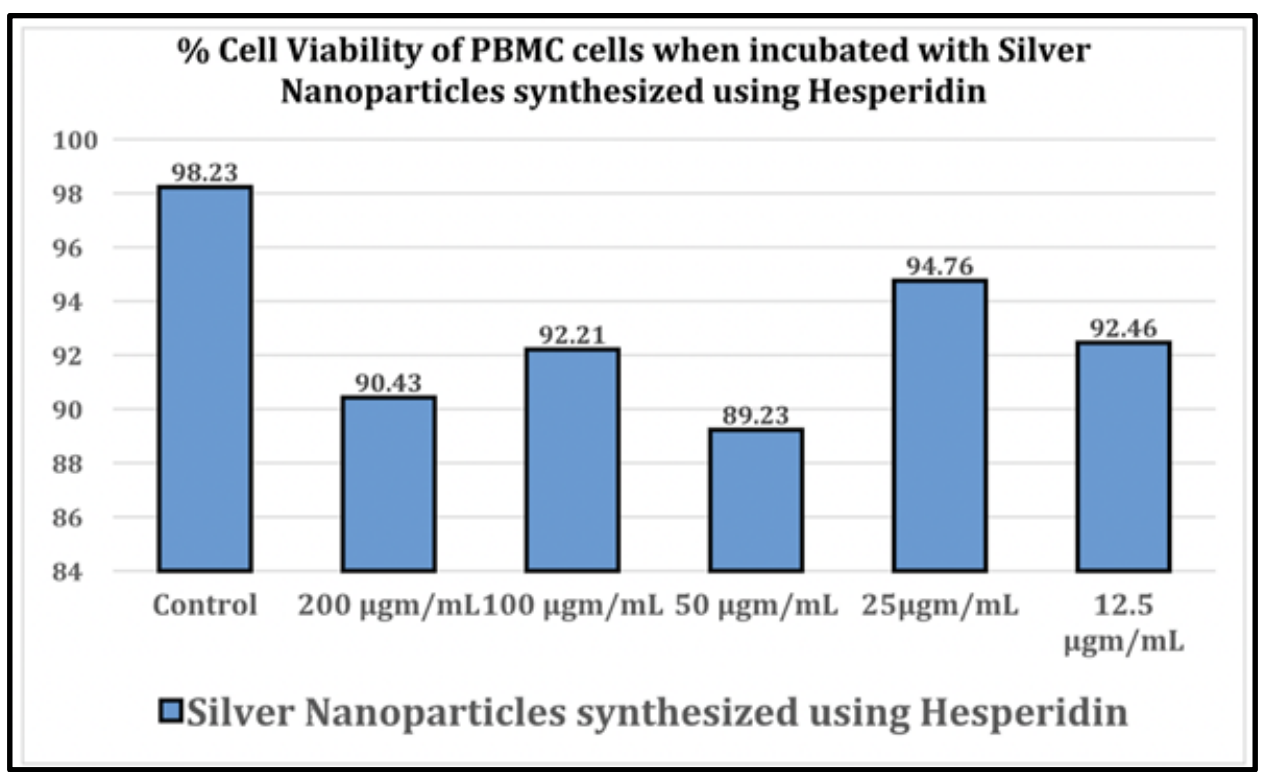

Figure 1: \% viability of PBMC cells when incubated with silver Nanoparticles synthesized using Hesperidin 
Annals of International Medical and Dental Research

E-ISSN: 2395-2822 | P-ISSN: 2395-2814

Vol-8, Issue-1 | January-February 2022

DOI: $10.53339 /$ aimdr.2022.8.1.25

Page no- 00-00 | Section- Research Article (Pharmacology)

Table 1: \% viability of PBMC cells when incubated with silver Nanoparticles synthesized using Hesperidin

\begin{tabular}{|l|l|}
\hline Concentration & \% Viability of PBMC cells \\
\hline Control & $98.23+/-1.33 \%$ \\
\hline $200 \mathrm{ug} / \mathrm{mL}$ & $90.43+/-2.91 \%$ \\
\hline $100 \mathrm{ug} / \mathrm{mL}$ & $92.21+/-1.30 \%$ \\
\hline $50 \mathrm{ug} / \mathrm{mL}$ & $89.23+/-2.66 \%$ \\
\hline $25 \mathrm{ug} / \mathrm{mL}$ & $94.76+/-4.91 \%$ \\
\hline $12.5 \mathrm{ug} / \mathrm{mL}$ & $92.46+/-3.21 \%$ \\
\hline
\end{tabular}

\section{Statistical Analysis}

Wilcoxon signed-rank test the other values do not significantly differ from the control value of 98.230 the two-tailed p-value is 0.0625, considered not quite significant.

\section{DISCUSSION}

The cytotoxicity of silver nanoparticles was studied using MTT assay. The percentage viability of the peripheral blood mononuclear cells (PBMC) after incubation with various concentrations of silver nanoparticles synthesized using Hesperidin was used as an indicator to quantify the cytotoxic potential. The serial concentrations of silver nanoparticles used are the same concentrations in which the in vitro assays are generally conducted. The results of the study showed that in the dose range of $12.5 \mu \mathrm{g} / \mathrm{mL}$ to $200 \mu \mathrm{g} / \mathrm{mL}$, the percentage cell viability was more than $89 \%$ and there was no dose-dependent activity seen and also there was no significant difference with the control values (confirmed by statistical analysis p-value 0.0625) and these results can form the basis of dose selections in further Invitro assays to evaluate the other pharmacological activities. There is also a totally opposite perspective on cytotoxicity in which if a product exhibits
Cytotoxic properties then it can be a candidate for anti-tumour studies. Based on the available literature review, If the concentration of the silver nanoparticles is increased there can be a cytotoxic effect on cell viability which can play a major role in antitumor activity, thereby reducing disease progression. [18] In a recent study, the Rat coronary endothelial cells exposed to doses of Ag NPs $(100 \mu \mathrm{g} / \mathrm{ml})$ for a period of 24 hours responded with increased production of nitric oxide, resulting in cell proliferation. At lower doses $(<10 \mu \mathrm{g} / \mathrm{ml})$, only a decrease in mitochondrial function was observed.19] Our study has not specifically investigated the expression of inflammatory markers or cellular enzymes but Cellular Viability per se has been considered central to analyze the toxicity of the Silver Nanoparticles.'

\section{CONCLUSIONS}

It was observed that there did not exist any significant cytotoxicity on the PBMC by the silver nanoparticles with which they were incubated and there was no dose-dependency trend observed. This study can form a basis for conducting Acute, SubAcute and Chronic Toxicity studies as per the OECD Guidelines. 
Annals of International Medical and Dental Research

E-ISSN: 2395-2822 | P-ISSN: 2395-2814

Vol-8, Issue-1 | January-February 2022

DOI: 10.53339/aimdr.2022.8.1.25

Page no- 00-00 | Section- Research Article (Pharmacology)

\section{REFERENCES}

1. Sarkar PK, Chaudhary AK. Ayurvedic Bhasma: the most ancient application of nanomedicine. J Sci Ind Res. 2010; 69(12): 901-905.

2. Burdușel AC, Gherasim O, Grumezescu AM, Mogoantă L, Ficai A, Andronescu E. Biomedical Applications of Silver Nanoparticles: An Up-to-Date Overview. Nanomaterials $\quad$ (Basel). 2018;8(9):681. doi:10.3390/nano8090681

3. Ruparelia JP, Chatterjee AK, Duttagupta SP, Mukherji S. Strain specificity in antimicrobial activity of silver and copper nanoparticles. Acta Biomater. 2008;4(3):70716. doi: 10.1016/j.actbio.2007.11.006.

4. Nanda A, Saravanan M. Biosynthesis of silver nanoparticles from Staphylococcus aureus and its antimicrobial activity against MRSA and MRSE. Nanomedicine. 2009;5(4):452-6. doi: 10.1016/j.nano.2009.01.012.

5. Maneerung T, Tokur S, Rujiravanit R. Impregnation of silver nanoparticles into bacterial cellulose for antimicrobial wound dressing Carbohydrate Polymers. Carbohydr Polym. 2008;72(1):43-51. https://doi.org/10.1016/j.carbpol.2007.07.025.

6. Brandt $\mathrm{O}$, Mildner $M$, Egger AE, Groessl M, Rix U, Posch M, et al. Nanoscalic silver possesses broadspectrum antimicrobial activities and exhibits fewer toxicological side effects than silver sulfadiazine. Nanomedicine. 2012;8(4):478-88. doi: 10.1016/j.nano.2011.07.005.

7. Lara $\mathrm{HH}$, Ayala-Nuñez NV, Ixtepan-Turrent L, Rodriguez-Padilla C. Mode of antiviral action of silver nanoparticles against HIV-1. J Nanobiotechnology. 2010;8:1. doi: 10.1186/1477-3155-8-1.

8. Galdiero S, Falanga A, Vitiello M, Cantisani M, Marra V, Galdiero M. Silver nanoparticles as potential antiviral agents. Molecules. 2011;16(10):8894-8918. doi:10.3390/molecules16108894

9. Rogers JV, Parkinson CV, Choi YW, Speshock JL, Hussain SM. A Preliminary Assessment of Silver Nanoparticle Inhibition of Monkeypox Virus Plaque Formation. Nanoscale Res Lett. 2008;3(4):129-133. doi:10.1007/s11671-008-9128-2

10. Papp I, Sieben C, Ludwig K, Roskamp M, Böttcher C, Schlecht $S$, et al. Inhibition of influenza virus infection by multivalent sialic-acid-functionalized gold nanoparticles. Small. 2010;6(24):2900-6. doi: 10.1002/smll.201001349.

11. Lu L, Sun RW, Chen R, Hui CK, Ho CM, Luk JM, et al. Silver nanoparticles inhibit hepatitis $B$ virus replication. Antivir Ther. 2008;13(2):253-62.

12. Panácek A, Kolár M, Vecerová R, Prucek R, Soukupová J, Krystof V, et al. Antifungal activity of silver nanoparticles against Candida spp. Biomaterials. 2009;30(31):6333-40.

doi: 10.1016/j.biomaterials.2009.07.065.

13. Nasrollahi A, Pourshamsian K, Mansourkiaee P. Antifungal activity of silver nanoparticles on some of fungi. Int J Nano Dim. 2011;1(3):233-239.

14. Ponarulselvam S, Panneerselvam C, Murugan K, Aarthi N, Kalimuthu K, Thangamani S. Synthesis of silver nanoparticles using leaves of Catharanthus roseus Linn. G. Don and their antiplasmodial activities. Asian Pac J Trop Biomed. 2012;2(7):574-580. doi:10.1016/S2221-1691(12)60100-2

15. Park MV, Neigh AM, Vermeulen JP, de la Fonteyne LJ, Verharen HW, et al. The effect of particle size on the cytotoxicity, inflammation, developmental toxicity and genotoxicity of silver nanoparticles. Biomaterials. 2011;32(36):9810-7. doi: 10.1016/j.biomaterials.2011.08.085.

16. Maneewattanapinyo $P$, Banlunara $W$, Thammacharoen C, Ekgasit S, Kaewamatawong T. An evaluation of acute toxicity of colloidal silver nanoparticles. J Vet Med Sci. 2011;73(11):1417-23. doi: 10.1292/jvms.110038.

17. Stephen A, Seethalakshmi S. Phytochemical Synthesis and Preliminary Characterization of Silver Nanoparticles Using Hesperidin. J Nanosci. 2013; 2013(126564):

$1-6$. https://doi.org/10.1155/2013/126564.

18. Walker F. Experimental argyria: a model for basement membrane studies. Br J Exp Pathol. 1971;52(6):589-93.

19. Rosas-Hernández H, Jiménez-Badillo $S$, MartínezCuevas PP, Gracia-Espino E, Terrones H, Terrones M, et al. Effects of 45-nm silver nanoparticles on coronary endothelial cells and isolated rat aortic rings. Toxicol Lett. 2009;191(2-3):305-13. doi: 10.1016/j.toxlet.2009.09.014.

Source of Support: Nil, Conflict of Interest: None declare 